\title{
The international experience in domestic mergers - Are purely domestic M\&A a myth?
}

\author{
Noelia-Sarah Reynolds (née Schnurr) ${ }^{a, 1}$, Satu Teerikangas ${ }^{b, 1, *}$ \\ ${ }^{a}$ Essex Business School, University of Essex, Wivenhoe Park, CO4 3SQ Wivenhoe, United Kingdom \\ ${ }^{\mathrm{b}}$ University College London (UCL), 1-19 Torrington Place, WC1E 7HB London, United Kingdom
}

\section{A R T I C L E I N F O}

\section{Article history:}

Received 30 June 2014

Received in revised form 15 June 2015

Accepted 10 July 2015

Available online $\mathrm{xxx}$

\section{Keywords:}

$\mathrm{M} \& \mathrm{~A}$

Merger

Acquisition

Emotions

Ethnography

\begin{abstract}
A B S T R A C T
Paralleling the rise of cross-border mergers and acquisitions (M\&As) over the last decades, the academic study of the international dimensions and challenges of cross-border M\&A has increased. This has led to a conceptual distinction between domestic M\&As on the one hand, and cross-border M\&As on the other hand. Our two ethnographic case studies on domestic mergers enable us to contradict this wellestablished assumption. We observe domestic mergers to be impacted by cross-border dimensions. These influences bear particular relevance on the merging organizations' employees' experience of the merger. In this light, the employee experience is deemed an international vs. domestic one. This leads us to posit that both academics and practitioners engaged with M\&As need to bear caution with respect to the established domestic vs. cross-border divide. Our main contribution claims that in a globalized environment, purely domestic M\&As are a myth. This finding bears important implications on the practice and theorizing on M\&As and international management at large.
\end{abstract}

(c) 2015 Elsevier Ltd. All rights reserved.

\section{Introduction}

Mergers and acquisitions (M\&A) have become an established means of strategic expansion for medium to large-sized firms across industries. Whilst in their early stages in the 1890s, M\&As were a domestic phenomenon concerning American enterprises, throughout the 20th century subsequent M\&A waves have come to include international (i.e. cross-border) transactions, as firms have sought international expansion through acquisitive activity (Hitt et al., 2012; Kolev, Haleblian, \& McNamara, 2012). In Europe, this trend was particularly noticeable in the 1990s, when the integration of the European Union fueled the take-off of European cross-border deals (Cartwright, 1998). More recently, the rise and international expansion of emerging market multinationals has been paralleled with heightened M\&A activity, be it by Chinese or Indian firms (Kale \& Singh, 2012).

This corporate activity has been paralleled with the academic study of M\&A (for recent reviews, see Faulkner et al., 2012; Gomes, Weber, Brown, \& Tarba, 2011; Haleblian, Devers, McNamara, Carpenter, \& Davison, 2009; Weber et al., 2012). Reflecting the

\footnotetext{
Corresponding author.

E-mail addresses: nschnurr@essex.ac.uk (N.-S. Reynolds (née Schnurr)), s.teerikangas@ucl.ac.uk (S. Teerikangas).

${ }^{1}$ Both authors are equal contributors to the paper.
}

development of M\&A in corporate practice, the distinction between domestic and international (or cross-border) transactions has prevailed. Much of the early theorizing on M\&As was thus conducted on domestic transactions; since the 1990s, an increasing interest has been placed on international transactions (Cartwright, 1998; Shimizu, Hitt, Vaidyanath, \& Pisano, 2004).

Whilst such a distinction might bear relevance for the practice of conducting an acquisitive transaction, its relevance for the purposes of theorizing on M\&As has rarely been questioned (Child, Faulkner, \& Pitkethly, 2001; Shimizu et al., 2004). In the academic study of M\&A, it is assumed that one can conceptually distinguish between the challenges faced by domestic vs. international acquisitions. International acquisitions are considered to bear the additional challenges of cultural (Stahl \& Voigt, 2008; Teerikangas \& Very, 2006), institutional (Geppert, Dörrenbächer, Gammelgaard, \& Tapli, 2013) and linguistic boundaries (Piekkari, Vaara, Tienari, \& Säntti, 2005; Vaara, Tienari, Piekkari, \& Säntti, 2005), whereas domestic acquisitions occur in more monotonous contexts, as they are not impacted by the afore-identified international variables.

Our paper challenges this assumption. The research question guiding the paper is: 'What are the international dimensions in domestic mergers and, further, how do such dimensions affect the employee experience in domestic mergers?' Our paper contributes to extant M\&A research as follows. To begin with, building on the 
arguments of Shimizu et al. (2004) and Child et al. (2001), our empirical work leads us to posit that in the contemporary global economic environment, the hitherto-held distinction between international vs. domestic M\&A does not hold. In contrast, our ethnographic involvement in two 'domestic' mergers in Northern Europe - one in the United Kingdom, one in Finland - enabled us to observe that both transactions were embedded in and impacted by the international, whether strategically, performance-wise, from the perspective of human resource management or work processes. Secondly, the international dimensions of these seemingly domestic transactions impacted the employees in both mergers - their emotional experience of the merger was embedded in an international context. Thirdly, through the practice of ethnography, our findings answer recent calls for the use of a broader array of qualitative methods in the study of M\&A. In the following sections, we proceed to a review of relevant literature, the research design and methods, the findings and, finally, the discussion.

\section{Literature review}

In this section, we undertake a review of how the distinction between domestic vs. cross-border (or international) transactions has been approached in extant research on M\&As.

Taking a chronological perspective, Cartwright (1998) observes that the study of M\&A evolved from the study of largely domestic deals in the United States. From the early 1990s, interest in crossborder European transactions arose, followed by an interest in Asian and emerging market M\&A activity since the 2000s (Kolev et al., 2012). In their review of extant research on international M\&As, Shimizu et al. (2004) argue that though cross-border M\&A have received increasing attention across disciplines in the last decades, this work has been fragmented with little explicit focus on the characteristics of cross-border M\&A activity. So what is that is known on the cross-border dimensions of M\&A activity? Let us proceed to an overview of this area of work.

In the international business literature, much effort has been placed on comparing acquisitions as a mode of entry to a foreign market as compared to joint ventures and wholly owned subsidiaries (Barkema \& Vermeulen, 1998; Brouthers \& Brouthers, 2000; Kogut \& Singh, 1988). In strategy research, the question as to whether cross-border M\&A are a higher-performing value-creation strategy than domestic M\&A has led to an ongoing debate (see review in Hitt et al., 2012). Intriguingly, the findings counter the prevailing knowledge that M\&As perform poorly; a number of studies have observed positive performance effects for foreign vs. domestic purchasers (Kang, 1993; Markides \& Ittner, 1994). Emerging market acquirers seem to out-perform acquirers from developed economies (Chakrabarti, Gupta-Mukherjee, \& Jayaraman, 2009; Gubbi, Aulakh, Ray, Sarkar, \& Chittoor, 2010). Beyond value-creation and market entry, strategy and international business scholars have studied the nature of decision-making in cross-border acquisitions. Factors such as geographic distance (Malhotra \& Gaur, 2014), country of origin effects (Geppert et al., 2013) and acquiring firm managers' early international exposure (Piaskowska \& Trojanowski, 2014) have been found to affect decision-making as regards control, ownership and risk when undertaking cross-border acquisitions.

From an organizational integration perspective, the nature of the $M \& A$ process in cross-border settings has been under study. Qualitative studies have focused on the nature of the cross-border M\&A process (Olie, 1994; Quah \& Young, 2005). More recently, the Chinese seller's perspective (Zeng et al., 2013), strategic discourse (Floris et al., 2013), and the impact of target evaluation on M\&A performance have been explored (Ahammad \& Glaister, 2013). Country-specific effects, e.g. as regards human resource management practices, have been identified (Gomes, Angwin, Peter, \&
Mellahi, 2012). In parallel, the M\&A activity of multinational firms has been explored. Whilst the traditional take is to focus on Western firms' M\&A strategies as in Kling et al. (2014), more recently interest in emerging market multinationals has emerged (Kale \& Singh, 2012).

As regards the sociocultural dimensions of M\&A activity, the bulk of theorizing on the international dimensions of M\&A activity has been undertaken under the cultural stream of research on M\&A. Whilst research across the social and management scientists have observed the presence of numerous cultures (including national, industrial, professional, organizational), research on M\&A has largely focused on national and organizational cultures only (see Teerikangas \& Very, 2006, for a review). We observe that this work assumes organizational culture to relate to domestic transactions, whereas the presence of national cultures points to cross-border transactions. In other words, this work distinguishes conceptually between domestic vs. cross-border M\&As with respect to the involved cultural challenges and dynamics.

What is it that we have learned from this inquiry? We can distinguish between research that has combined organizational and national cultures in the study of cross-border M\&A on the one hand, and research that has explicitly focused on national culture in cross-border M\&As on the other hand. Starting with the former, a major question has concerned whether organizational or national cultures, or perhaps their combination, has an impact on M\&A performance (Stahl \& Voigt, 2008; Teerikangas \& Véry, 2006; Teerikangas \& Véry, 2012) and M\&A processes, such as social conflict (Vaara, Sarala, Stahl, \& Bjorkman, 2012), knowledge transfer (Ahammad, Tarba, Liu, \& Gleister, 2014; Sarala, Cooper, Junni, \& Tarba, 2014) or emotional attending (Reus, 2012). The majority of work posits a mixed picture on the cultureperformance relationship (Stahl \& Voigt, 2008; Teerikangas \& Very, 2006). Recent advances observe that the relationship between culture(s) on the one hand, and M\&A processes and performance on the other hand, is mediated by factors including acquiring firm managerial attributions (Vaara, Junni, Sarala, Ehrnrooth, \& Koveshnikov, 2014), the acquirer's international acquisition experience (Dikova \& Sahib, 2013), acquirer multinationalism (Reus, 2012), human resources flexibility, inter-firm linkages (Sarala et al., 2014) and integration approach (Weber, Tarba, \& Reichel, 2009), whilst being moderated by sociocultural processes (Hajro, 2015). On the other hand, another stream of work has focused on cultural integration and cultural change following M\&As (for reviews, see Marks \& Mirvis, 2011; Teerikangas \& Véry, 2012). This line of work began by studying domestic M\&As (Buono \& Bowditch, 1989; Buono, Bowditch, \& Lewis, 1985; Cartwright \& Cooper, 1992; Sales \& Mirvis, 1984), whereas more recently attention has shifted to cross-border M\&As (Lakshman, 2011; Pioch, 2007; Styhre, Börjesson, \& Wickenberg, 2006; Teerikangas \& Laamanen, 2014; Weber \& Fried, 2011a; Weber \& Tarba, 2011).

In parallel, some work has focused on the impact and management national cultures in cross-border M\&As. The earliest findings were by Morosini and Singh (1994), who argued that acquiring firms need to tailor their integration approaches to the national culture of the target firm. Olie (1994) observed that national cultures are embedded in cross-border merger processes. Further, acquiring firms' due diligence (Angwin, 2000) and integration approaches following M\&As have been found to differ depending on their national cultural background (Calori, Lubatkin, \& Véry, 1994; Faulkner, Child, \& Pitkethly, 2003; Larsson \& Lubatkin, 2001; Weber, Tarba, \& Reichel, 2011). More recently, Barmeyer and Mayerhofer (2008) studied the intercultural dynamics following a tripartite European aerospatial merger. To deal with the cross-cultural challenges involved, Morosini (1998) calls for cross-cultural skills in the practice of cross-border M\&As. 
In parallel with these developments, attention has been paid to the human side of M\&A. The main focus in this line of work has been on the negative emotional experience, i.e. the anxiety and stress that major organizational upheavals such as mergers create in the involved organizations' employee bases (Cartwright \& Cooper, 1990; Kiefer, 2002; Weber \& Fried, 2011b). Less attention has been placed on the positive employee reactions incurred (Teerikangas, 2012). The question of whether domestic or crossborder deals result in higher levels of stress has produced conflicting evidence (Froese, Pak, \& Chong, 2007; Larsson \& Risberg, 1998; Véry, Lubatkin, \& Calori, 1996; Weber, Shenkar, \& Raveh, 1996).

Though the distinction between domestic and cross-border transactions is made, findings tend not to be divided along this line. Extant research suggests that culture shock (Buono et al., 1985; Buono \& Bowditch, 1989) and the type of post-deal change (Cartwright \& Cooper, 1992) influence employee reactions. Reus (2012) acknowledges the interplay between culture and emotional aspects of mergers. Whilst cases have been observed in which cultural concerns seem to impact little on employee emotions (Gunkel et al., 2015), Reus (2012) found that cultural differences in a cross-border merger impacted on how emotional employees felt. A significant body of work has focused on ways to overcome negative emotions that were seen as being related to organizational dysfunction, low performance, resistance and inertia (Appelbaum et al., 2000; Bruckman \& Peters, 1987; Marks \& Mirvis, 2001). Thus studies have, amongst other things, looked at the role of communication in emotions during M\&A (Ivancevich, Schweiger, \& Power, 1987; Scheck \& Kinicki, 2001; Schweiger \& Denisi, 1991), the influence emotions have on post-merger identification (van Dick et al., 2004), and the role of management behavior (Sinkovics et al., 2011). This stream of work considers both domestic (Clarke \& Salleh, 2011) and international (Sinkovics, Zagelmeyer \& Kusstatscher, 2011) mergers.

To summarize, our review of extant theorizing leads us to observe that there is no one stream of work that has a monopoly over the study of the cross-border dimensions of M\&A activity. Such research is, instead, scattered across several disciplines and lines of inquiry. What unites this work, though, is an implicit assumption that domestic and cross-border acquisitions differ with respect to their strategic, processual and cultural dynamics. The impact of the cross-border dimension on the employee experience has been observed, yet left to lesser attention.

In this paper we argue that in the contemporary globalized setting, making such clear-cut distinctions between what is a domestic vs. a cross-border transaction has become more difficult, if not an illusion. Our findings posit that all M\&As, including domestic ones, boast international dimensions. This bears an impact on the sociocultural dimensions of M\&A activity, e.g. as regards employee stress and emotions, as instead of experiencing a purely domestic deal, employees experience the international amid a domestic setting. We thus claim that purely domestic M\&As have become a myth. In so doing, we join Child et al.'s (2001) call for the need to appreciate the international dimensions of domestic M\&A activity. We also align with Shimizu et al.'s (2004) argument that there is a need to reframe what is meant by the cross-border activities - we observe that also domestic mergers bear cross-border characteristics. In short, the boundary of cross-border M\&As needs to be enlarged.

\section{Methodology}

The study of M\&A has been marked by an active debate about the need to theorize on M\&A (Greenwood, Hinings, \& Brown, 1994; Schweiger \& Goulet, 2000). A recent special issue was dedicated to qualitative innovations in the study of inter-organizational encounters, including M\&As (Cartwright, Teerikangas, Rouzies, \& Wilson-Evered, 2012). In a related vein, Meglio and Risberg (2010) call for more breadth in the methods used in the study of M\&A, critiquing particularly the study of M\&A performance (Meglio \& Risberg, 2011; Véry, 2011). Cartwright et al.'s (2012) review of the methods used in the study of M\&A posits a strong quantitative bias, totalling $80.7 \%$ of the published work in top academic journals. Where qualitative methods have been adopted, the focus is on single or multiple (Graebner \& Eisenhardt, 2004; Graebner, 2004; Schweizer, 2005) case studies (29.5\% and 52.5\% respectively of all qualitative studies). Studies undertaking an ethnographic approach remain in a minority, representing $3.2 \%$ of all published qualitative studies in top journals. This means that a majority of M\&A research undertakes an 'external' lens to the studied phenomenon, exploring M\&As through the lenses of interviewees or workshop participants. This led Cartwright et al. (2012) and Meglio and Risberg (2010) to call for more 'insider' perspectives to M\&A by undertaking ethnographic research. These calls parallel the rise of the ethnographic approach in organizational studies at large over the recent years (Watson, 2012; Schwartz-Shea \& Yanow, 2012).

In this paper, we respond to these calls for more ethnographic research in the study of M\&As. Our findings draw from two ethnographic case studies. Both cases could at first appearance be considered as domestic mergers. In both cases, our original aim was to appreciate the sociocultural dynamics (i.e. stress, emotions, culture, ...) involved in domestic mergers. Qualitative methods as discussed above have been successfully employed to understand employee reactions (Teerikangas, 2012) and willingness to cooperate (Melkonian, Monin, \& Noorderhaven, 2011) during M\&A. Studying the sociocultural dynamics of each case revealed hidden international aspects that explained the employee experience of the studied transactions. In both cases during the field work we realized that whilst each deal was presented by integration managers (Teerikangas, Very, \& Pisano, 2011) to employees as a domestic merger our informants repeatedly raised international aspects impacting on how they felt about the deal and future integration.

Ethnography is an ideal method to study such dynamics, since ethnography by definition involves the study of people, culture and perception. Ethnography enables connecting the spoken words of those that are being observed and the cultural organizational setting in which these words occur (Watson, 2012). Since the main aim of ethnography is to understand the "cultural whole" (Watson, 2012:17), the place in which we do our fieldwork, ethnography enables a deep understanding of both the research context and the specific aspect that is being studied (Gellner \& Hirsch, 2001). The data we draw on are ethnographic observations and interactions that we engaged in while we were in the field. Hence, an ethnographic research design was well suited to approach our initial research questions.

\subsection{Cases and data collection}

Both mergers that we studied are set in Northern Europe, one in the United Kingdom, the other in Finland. This choice arose from practical concerns, as access to merging organizations is hard to negotiate. In both cases, the researcher(s) were well placed for the study of an unfolding merger. In the first merger, the second author was working for the one of the merging partners. As the merger was announced, she became part of a research team studying the merger. In the second merger, the first author was already studying one of the merging partners - the focus of the ethnography shifted toward mergers after the transaction was announced.

The first case study is an auto-ethnographic study of a tripartite North-European university merger in Finland. The second author was engaged in the merger in three roles: first, as a 'recipient' of the 
change; second, as a 'researcher' observing the unfolding of the merger; and third, as an 'internal change agent', participating in one of the inter-university integration teams.

Regarding the latter two roles, the findings draw from the second author's experience of participating in a pre-merger integration planning team over a ten month period in 20082009. The second author was appointed in a post-doctoral, expert role in the team in charge of coordinating the development of the mission, vision and values statements for the new university. The team's task consisted of pulling together ideas and feedback received from a larger inter-university senior support team, an external reference group, the university's rectors and the university board, the integration program's leadership team, and the three universities' faculty, students and stakeholders through various workshops and two consecutive web-based surveys. This feedback process came to characterize the forthcoming university in that it was to become a modern, innovative and participative organization. This ideal was ingrained into the integration planning process.

In this period, paralleling her role as integration team member, the second author undertook an ethnographer's role. First, she observed the events, people and interactions as the integration planning work evolved, and kept field notes of her observations (Atkinson \& Hammersley, 1994; Van Maanen, 1988). Second, in the form of auto-ethnography (Ellis \& Bochner, 2000), she further kept track of her own feelings and thoughts in separate field notes. As an additional source of data, nine months after the completion of the team's work, she interviewed the studied integration team's members. Throughout the merger process, in addition, a multiplicity of internal and external documents was gathered. All written evidence on the making of the university's mission, vision and values statements was kept.

The second case concerns a domestic merger within the UK telecommunication industry, involving European parent companies. The first author studied one of the two merging UK organizations for a period of 20 months. She was fortunate to gain access to the live unfolding of this merger, as she was already engaged in research with the company when the deal was announced. Research began with observations of events, people and organizational culture, which were written up as field-notes. The data set for this study comprised these notes together with the first author's own reflections. Unlike the above case, the ethnographer was initially an outsider to the company, however through her regular presence in the organization's headquarters, she had gradually become more broadly known by the organizational members.

\subsection{Data analysis}

The analysis of our data followed an abductive process. Both case studies were conducted on merger deals that a priori seemed domestic. However in the course of the ethnographic work, we realized that when studying sociocultural dynamics and how people experienced the mergers, unexpected international dimensions were revealed. This led us to return to the literature to investigate how mergers considered as domestic might come to bear international dimensions. By maintaining a focus on the employees experiencing the mergers, we then sought to identify when and why observees experienced an event or occurrence as international. In both cases during the field work we realized that whilst both deals were classed as domestic, our informants made ongoing reference to the international dimensions involved. This impacted on how they felt about the deal and its future, in particular the anxiety and stress this caused them. In order to identify the international dimensions we looked for evidence of where employees talked about such aspects and how this impacted on how they felt. This coding was inductive. We conducted this analysis for both cases. In the following, we provide an overview of the main findings that emerged from this analysis.

\section{The international dimensions of domestic mergers}

As our ethnographic work proceeded, our appreciation of both mergers as purely domestic started to ebb. A further analysis of the emerging findings led us to fine-tune our initial largely domestic appreciations of both the university merger and the telecommunications merger. We observed that international dimensions were present in both mergers. The analysis of the two ethnographic case studies of domestic mergers led us to identify that these domestic mergers were impacted by the international as regards: (1) the logic and drivers of the transactions, (2) the newly merged organizations' strategic direction, (3) talent management, (4) work processes, and (5) outputs. The presence of these international dimensions might have not have been as important had it not been for their consequences on the employees' experience of the mergers. We observed that the international dimensions explained the causes of stress and anxiety amongst to the employee base. It is thus that their presence could not be ignored.

\subsection{International influence \#1: transaction logic and drivers}

The first international influence mechanism that we identified as impacting the seemingly domestic mergers related to the logic and drivers of the mergers. In both cases we found evidence that, though from the perspective of organizational integration the implementation of the mergers occurred on domestic grounds, if looked at from the larger contextual perspective, both mergers were embedded in an international logic. We begin our analysis with the university merger, moving onto the telecommunications merger.

As with much of the global M\&A activity across industries (Hitt et al., 2012; Kolev et al., 2012), the drivers of the university merger reflected globalization. In the case of the university merger the competitiveness of nations and a toughening academic institutional battle - both increasingly played out against a global arena were at play. Faced with competition from lower cost economies, Nordic industries have been seeking means of renewal through a focus on innovation and the use of human and knowledge-based capital. A similar trend has been reflected at the level of Nordic societies; they consider their long-term survival to depend on the extent to which the societies can, collectively, transfer toward knowledge-based modes. Faced with such pressures, notwithstanding, the role of the countries' leading universities becomes quintessential. The Finnish institutional stakeholders observed in 2006-2007 that the country's long-term turn toward innovation needs to be sparked by its leading academic establishments. This paralleled debates at the level of the European Union, where increasing M\&A activity amid university institutions had been observed since the early 21 st century. The aim of the newly created university was to intellectually spearhead the country's survival amid an increasingly toughening global game.

For the employees, the arrival of the new university represented the explicit end of a previously domestic university institutional ethos. Pressure was felt by employees across the organizations, whether at incoming, junior or senior faculty levels or as regards professional services staff. The international context amidst which the merger had been created became a source of stress and anxiety. In the years preceding and following the merger, the international context was present in daily professional and informal discussions. Employees were genuinely worried about how the global context would impact them.

In the second case, the merger of two domestic telecommunication companies was fueled by their international parent 
companies. Both domestic companies were too small to compete with larger rivals in their marketplace and hence were pressured by their parent companies to merge. Prior to the period of the ethnographic study, there had been significant speculation that the parent companies would want to sell the firms or engage in a merger deal if their competitive position did not improve, in order to give the parent company a stronger international presence.

Despite these international pressures to merge, managers in both firms treated the merger as a domestic transaction. All the while, it became clear in employees' reflections that they felt that the managers had to justify themselves to the parent company. During the period of study, there was anxiety in terms of what this meant for the employees:

"I mean I feel there's a lot of pressure to make this work from the ones abroad, otherwise will they just sell us on?.... and then we might not survive as we are..."

In sum, we observe that through occurring domestically, both mergers were set up against a global competitive arena. Without the international landscape of competition facing nations neither merger would have occurred. The international landscape affected the emotional experience of the employees, who felt more pressured and challenged, as they were facing global competition and an uncertain future.

\subsection{International influence \#2: strategic direction}

The second international influence mechanism that we identified as impacting the seemingly domestic mergers related to the strategic direction of the newly merged organizations. This mechanism was particularly visible in the university merger.

The newly merged organization's strategy came to reflect the international context amid which the merger transaction occurred. The university's strategy, though executed locally, was set to enable the university to face the global competitive context. First, the university sought competitive edge by focusing on innovation through the interdisciplinary mix that defines its academic bases. Innovation was at the core of the university's teaching, research and impact strategies. In so doing, the university sought to parallel Finland's developments since the 1990s toward a knowledgebased society. Second, reflecting the toughening and increasingly internationalizing academic competitive arena, the newly created university sought to fight its way onto leading universities' rankings worldwide. Here, its task was not to be under-estimated; the founding universities' rankings on university rankings did not make it to the top 300s. Much needed to change, and the university sought to enhance its ways of recruiting, operating and rewarding in order to secure a more competitive ranking. These quests were visible in the university's new mission, vision and values statements, which portrayed the notions of science-based competition via an innovative agenda. The newly formed university's draft mission statement read in spring 2009:

"The University strives to change the world through renowned research and education, and by providing pioneering expertise. It will promote the courage to cross borders and pursue renewal. The university's graduates are responsible and independent experts who then serve as visionaries in society."

The new strategic direction was met with enthusiasm and eagerness by some, and by uncertainty and scorn by others. A survey of the universities' employees in spring 2009 highlighted a 50/50 split between the two camps.

In summary, the newly defined strategic positioning of the studied university merger highlights how in a seemingly domestic merger, the strategic direction of the newly formed organization needs to be set within an international remit.

\subsection{International influence \#3: talent management}

The third international influence mechanism that we identified as impacting the seemingly domestic mergers related to talent management. We begin our appreciation of the international dimensions of talent management in the university merger, moving thereafter onto talent management in the telecommunications merger.

In terms of their talent pool, internationally leading universities recruit the world's best talent globally, without relying on domestic talent only. In this respect, the Finnish university scene can be considered as being, at the time of the merger, severely delayed as regards the intake of international faculty. Recruitment practices had over the years come to favor local talent. As the newly merged university was seeking to up its game on the international university rankings, this bore consequences on the future university's academic talent pool. The human resources and recruitment strategies and targets came to reflect the university's strategy. The aim was to attract international talent into Finland whilst prompting the international mobility of local talent. Though this is standard practice in larger-sized countries such as the United States, the United Kingdom, France or Germany, this decision caused much stir amid the academic community. Academics at all levels of seniority (from assistant, associate to full professors) came to fear for their jobs. Graduating doctoral students began to seek overseas positions. Non-tenured academics followed suite. In the early years of the merger, much of the turnover of existing talent reflected a seeming frustration with a university discourse of "seeking the best", whilst little effort appeared to be made to secure the commitment of existing talent. Existing talent did not seem to be worth much, until further proven. The mantra "we need the best international talent" was implicitly read to assume that talent by definition is international, not local. Notwithstanding, some of the existing talent left for international positions overseas.

The international dimensions of human resource issues also played out in the telecommunications merger. As earlier illustrated, the merger arose due to pressure from the parent companies to improve performance. Once it had been decided that a merger was the means of achieving this goal, the parent companies took a close interest in the management of the merger - this interest included the talent required to implement the process. Although the parent companies did not seek international talent, they took control over decision-making regarding who would manage the merger process. In particular, a new senior manager was brought into one of the firms. This generated a cycle of concern amongst employees - they were worried as to what would happen to their jobs in the future? Was it likely that the parent company would replace them, would jobs be lost overseas? As the parent companies could now draw from a much larger international talent pool, employees worried that this would mean stronger competition if employees were ever asked to ask to apply for their own jobs as part of the merger, as illustrated in the quote below:

"... it is a worry, you know, they are making a lot of decisions for us, and next time it could be 'we need to move you' or replace you even may be with someone international ... so yeah I think most people must be a bit worried. You know there are a lot more good people if we can get them from anywhere in the world, not just the UK"

In summary, in both of the studied domestic mergers, we observed that employees became increasingly concerned about the security and longer-term tenure of their jobs. Their concerns were fueled by the international context amid which both mergers took place. Talent-related concerns were a source of much of the stress and anxiety expressed in the pre- and post-merger eras in both cases. 


\subsection{International influence \#4: work processes}

The fourth international influence mechanism that we identified as impacting the seemingly domestic mergers related to work processes within the merged organizations.

The merger resulted in the enhancement of work processes in the studied university merger. The pre-merger due diligence team had been tasked with conducting a benchmarking exercise on how the world's leading universities were administered. Among the findings was the professionalism of their work processes as regards teaching, research, impact and professional services. It is thus that pre and post-merger, the merging organizations engaged in a major exercise to revamp the newly formed university's work processes to match those of world leading universities. To begin with, the central administrative team's headcount was increased, particularly in areas such as corporate communications and marketing. The impact of the new work processes was particularly felt by administrators and department heads, who complained about the additional workload created by more cumbersome processes. The quote below from a department head exemplifies this concern:

"In the spirit of engagement and empowerment, each department is now being asked to contribute to the university's strategic directions. Whilst this is positive, it is all additional effort to our already busy schedules as academics and department heads. Where do we find the time for this?"

In the telecommunications merger, the parent companies' search for enhanced performance from the merged entity resulted in the creation of new work processes and increased interactions between employees in the domestic (UK) sites and employees from across the parent organizations' global operations. Beyond the challenge of enhanced performance, the parent organizations were also keen to have a say on the organizational processes taking place in the new company. Employees involved both in merger integration processes and in the day-to-day business of the new organization described annoyance that having to report activities to the parent organization generated extra work, slowed work down and resulted in wasted effort:

"I do feel we have to do more now, in terms of reporting, you know these things all have to get signed off by [parent company] as well as by us... it's frustrating because you might put in all the effort but then they don't approve it."

\subsection{International influence \#5: outputs}

The fifth and final international influence mechanism that we identified as impacting the seemingly domestic mergers related to talent management.

In the university merger, stemming from the strategy of internationally reputed performance, the aim was for academics to conduct internationally recognized, leading-edge research, as measured by publications and citations in top-tier outlets. Whilst this was already the case in many of the merging universities' departments, the aspiring goal was met with fear and uncertainty by those individuals and departments, whose work remit did not adhere to quality standards as measured by top-tier outlets. The goal further transpired into the university's restructuring effort in that high-performing departments received investments and tenure-track positions, whilst lesser performing departments felt that they were being ousted from the university's strategic agenda. Notwithstanding, a cultural change toward high performance, coupled with an innovative touch, came to mark the university's early years and meant again that stress and anxiety was common amongst employees. One of the new value statements of the university read: "Courage to make an impact and excel."
A key driver for the telecommunications merger was for the domestic merger to improve the financial performance of the international parent organizations. Whilst the domestic firms were used to being ranked against other UK firms, they were now further the focus of increased attention regarding their contribution to the international marketplace. They became benchmarked against a wider variety of organizations - not only domestic and international competitors, but also in terms of the contribution they made to the parent company vis-à-vis its other international subsidiaries. This new context generated stress for the employees used to a domestic orientation. On the one hand, they lacked knowledge of the parent companies' activities in other countries to be able to appreciate what was being required of them. On the other hand, they had to get used to being more closely monitored for performance. The following quote illustrates these concerns:

"It's all about cutting costs, working with [the merging company], they want us to look at what they have managed to do in France or Germany - but I cannot see how that is relevant here."

In summary, in both domestic mergers, the international context amid which the mergers were undertaken came to have an effect on the sought outputs from the merged organizations. In both studied cases, the employee experience was that higher performance was expected in the international as compared to the domestic context. This created stress and anxiety amid the employees.

\section{Discussion}

Amid an era of globalization, M\&As have developed from an early domestic phenomenon to include an increasing number of international transactions. This has led the academic community to conceptually distinguish between domestic transactions on the one hand, and cross-border transactions on the other hand. This conceptual distinction has been found to hold particularly as regards the strategic, processual and cultural considerations of $M \& A$, whereas its effects on the human side of M\&A remain mixed. In this paper, we explored the employee experience in two domestic mergers in Northern Europe - one academic and one industrial merger - using an ethnographic approach. Our findings bear three contributions to the study of M\&A.

The main contribution of the paper is to empirically posit that domestic mergers bear international (i.e. cross-border) characteristics. This finding contradicts the implicit assumption guiding much M\&A research - that domestic M\&A transactions can be conceptually distinguished from cross-border transactions. Extant research has based this distinction on institutional, cultural, and linguistic grounds (Geppert et al., 2013; Stahl \& Voigt, 2008; Vaara et al., 2005). Our ethnographic study of two domestic mergers posits that though occurring within the remit of national frontiers, both mergers were in fact embedded in international contexts. This came to bear consequences on the strategic management, talent management, work processes and performance levels sought from both mergers. We join the calls of Child et al. (2001) and Shimizu et al. (2004) for the need for an enlivened discussion on what is domestic vs. cross-border in M\&A. In particular, our findings call M\&A scholars to be wary of the implicit assumptions guiding the work of the scholarly community. In particular, we call for academics to pay attention to the international dimensions in domestic mergers.

The second contribution is to recognize that the employee experience in domestic mergers is not only affected by the domestic, but also by the international context in which the merger occurs. Our ethnographic insights from two domestic mergers enabled us to observe that the international dimensions of both mergers in terms of context, strategy, talent, work processes, and performance targets affected the employee experience of the 
mergers. Instead of an expected domestic experience, in our conversations and interviews with employees in both mergers, we recognized that much of the emotionality at play could be traced back to the international dimensions of the transactions. Such an insight is, to the best of our knowledge, missing from extant M\&A research. Whilst the human side of M\&A has received a wealth of scholarly attention since the 1980 s, both as regards domestic (Buono \& Bowditch, 1989; Cartwright \& Cooper, 1990; Napier, 1989) and cross-border (Froese et al., 2007) transactions, the question as to whether the employee experience in cross-border transactions is different from that in domestic transactions remains open to debate (Teerikangas, 2012). Our findings enable us to contribute to this debate by observing that instead of the expected difficulty of the cross-border M\&A experience, the domestic merger experience ought not be treated as a domestic one, as it is equally affected by the international.

Our third contribution is a methodological one. Reviews posit that the overwhelming majority of M\&A research is based on US archival data (Haleblian et al., 2009; Papadakis \& Thanos, 2010; Thanos \& Papadakis, 2012). In light of the calls for a methodological rejuvenation of M\&A research (Meglio \& Risberg, 2011) and for the need for in-depth qualitative explorations of M\&A (Cartwright et al., 2012; Haleblian et al., 2009), our findings highlight the power of the ethnographic method in the study of M\&A. The review of the qualitative study of M\&A in Cartwright et al. (2012) highlights the scant use of ethnographic methods. Recent qualitative contributions have been made using multiple case study (Graebner \& Eisenhardt, 2004; Graebner, 2004; Schweizer, 2005), longitudinal (Melkonian et al., 2011) or grounded theory approaches (Teerikangas et al., 2011; Teerikangas, 2012). The nature of our ethnographic findings offers a ray of hope for the scholar considering the use of such methods. We observed that when conducting ethnographic work, the researcher is able to bypass existing labels and existing assumptions, as s/he needs to study the phenomenon 'in situ'. It is through such an open-ended, emergent approach that we came to appreciate our findings.

For the practicing corporate or institutional manager, the paper is a call to tread the domestic vs. cross-border divide with caution. Whilst extant research tends to caution engaging in cross-border transactions, our findings remind of the challenge of partnering at home. Beyond purely national and domestic concerns, we recommend managers to recognize the international dimensions bearing upon seemingly domestic partnerships. This attention is particularly relevant in order to empathize with the employees' experience of merging. Our findings suggest five areas that managers need to acknowledge in their communications with employees. Put bluntly, we argue that the domestic experience of a domestic merger has become obsolete.

Given the global nature of the contemporary business environment, the findings can be expected to resonate in other domestic mergers. Our cases posit that international dimensions are equally present in academic and industry mergers, whether occurring in the Nordic countries or the United Kingdom. All the while, we argue that our findings are likely to particularly resonate with mergers occurring in small-to-medium sized developed countries, as in the example here of the United Kingdom and Finland. Both countries are faced with increasing competition from emerging market players. Under such conditions, domestic mergers are likely to portray effects such as the ones identified in this paper.

Despite maintaining momentum, we recognize that our findings remain explorative and tentative. Our analysis is based on two in-depth, ethnographic case studies, set in particular country contexts. Further work is required to expand on the present findings across other contexts. The particular characteristics of our two cases also warrant consideration. The first case concerns a merger of university institutions. Though a wealth of material was gathered, the research was conducted by a researcher set within the organization. The second case is based on informant interpretations, thereafter interpreted by the external ethnographer.

Going forward, we call for more inquiry into the cross-border vs. domestic divide in M\&A research and, more broadly speaking, in the international business literature, where such distinctions are equally in use. What are the international implications in domestic alliances or joint ventures? Beyond affecting the employee experience, what further implications does the international context offer to seemingly domestic transactions? If the international is omnipresent in today's contemporary world, have purely domestic transactions become obsolete? If this is the case, is it time to redraw the boundaries in the academic study of modern organizations? Is there space for the domestic in the global contemporary society, and if yes, what form does it take? We look forward to an inspired and active research agenda going forward.

\section{References}

Ahammad, M. H., \& Glaister, K. W. (2013). The pre-acquisition evaluation of target firms and cross-border acquisition performance. International Business Review, 22(5), 894-904.

Ahammad, M. H., Tarba, S. H., Liu, Y., \& Gleister, K. W. (2014). Knowledge transfer and cross-border acquisition performance. International Business Review. http:// dx.doi.org/10.1016/j.ibusrev.2014.06.015 Advance online publication 15 July 2014.

Angwin, D. (2000). Mergers and acquisitions across European borders: National perspectives on pre-acquisition due diligence and the use of professional advisers. Journal of World Business, 36(1), 32-57.

Appelbaum, S. H., Gandell, J., Yortis, H., Proper, S., \& Jobin, F. (2000). Anatomy of a merger: Behavior of organizational factors and processes throughout the preduring- post-stages (part 1). Management Decision, 38(9), 649-661.

Atkinson, P., \& Hammersley, M. (1994). Ethnography and participant observation. Handbook of Qualitative Research, 1(23), 248-261.

Barkema, H. G., \& Vermeulen, F. (1998). International expansion through start-up or acquisition: A learning perspective. Academy of Management Journal, 41(1), 7-26.

Barmeyer, C., \& Mayerhofer, U. (2008). The contribution of intercultural management to the success of international mergers and acquisitions: An analysis of the EADS group. International Business Review, 17(1), 28-38.

Brouthers, K. D., \& Brouthers, L. E. (2000). Acquisitions or greenfield start-ups? Institutional, cultural and transaction cost influences. Strategic Management Journal, 21(1), 89-97.

Bruckman, J., \& Peter, S. (1987). Mergers and acquisitions: The human equation. Employment Relations Today, 14(1), 55-63.

Buono, A. F., Bowditch, J. L., \& Lewis, J. W. (1985). When cultures collide: The anatomy of a merger. Human Relations, 38, 477-500

Buono, A. F., \& Bowditch, J. L. (1989). The Human side of mergers and acquisitions: Managing collisions between people, cultures and organizations. London: JosseyBass.

Chakrabarti, R., Gupta-Mukherjee, S., \& Jayaraman, N. (2009). Mars-Venus marriages: Culture and cross-border M\&A. Journal of International Business Studies, 40, 216-236.

Calori, R., Lubatkin, M., \& Véry, P. (1994). Control mechanisms in cross-border acquisitions: An international comparison. Organisation Studies, 15(3), 361-379.

Cartwright, S., \& Cooper, C. L. (1990). The impact of mergers and acquisitions on people at work: Existing research and issues. British Journal of Management, 1, 65-76.

Cartwright, S., \& Cooper, C. L. (1992). Managing mergers, acquisitions and strategic alliances: Integrating people and cultures. Oxford: Butterworth-Heinemann.

Cartwright, S. (1998). International mergers and acquisitions: The issues and challenges. In M. Gertsen, A.-M. Söderberg, \& J. E. Torp (Eds.), Cultural dimensions of international mergers and acquisitions (pp. 5-16). Berlin: De Gruyter.

Cartwright, S., Teerikangas, S., Rouzies, A., \& Wilson-Evered, E. (2012). Methods in $M \& A-A$ look at the past and the future to forge a path forward. Scandinavian Journal of Management, 28(2), 95-106.

Child, J., Faulkner, D., \& Pitkethly, R. (2001). The management of international acquisitions, Oxford: Oxford University Press.

Clarke, N., \& Salleh, N. M. (2011). Emotions and their management during a merger in Brunei. Human Resource Development International, 14(3), 291-304.

Dikova, D., \& Sahib, P. (2013). Is cultural distance a bane or boon for cross-border acquisition performance? Journal of World Business, 48(1), 77-86.

Ellis, C., \& Bochner, A. P. (2000). Autoethnography, personal narrative, reflexivity: Researcher as subject. In N. K. Denzin \& Y. S. Lincoln (Eds.), Handbook of qualitative research (2nd ed., pp. 733-768). Thousand Oaks, CA: Sage.

Faulkner, D., Child, J., \& Pitkethly, R. (2003). Organisational change processes in international acquisitions. In C. Cooper, \& A. Gregory (Eds.), Advances in mergers and acquisitions (Vol. 1, pp. 59-80). Amsterdam: JAI Press. 
Faulkner, D., Teerikangas, S., \& Joseph, R. (2012). Handbook of mergers and acquisitions. Oxford: Oxford University Press.

Floris, M., Grant, D., \& Cutcher, L. (2013). Mining the discourse: Strategizing duuring BHP Billiton's attempted acquisition of Rio Tinto. Journal of Management Studies, 50(7), 1185-1215.

Froese, F. J., Pak, Y. S., \& Chong, L. C. (2007). Managing the human side of crossborder acquisitions in South Korea. Journal of World Business, 43, 97-108.

Gellner, D. N., \& Hirsch, E. (2001). Inside organizations: Anthropologists at work. Oxford: Berg.

Geppert, M., Dörrenbächer, C., Gammelgaard, J., \& Tapli, I. (2013). Managerial risktaking in international acquisitions in the brewery industry: Institutional and ownership influences compared. British Journal of Management, 24, 316-332.

Gomes, E., Weber, Y., Brown, C., \& Tarba, S. Y. (2011). Mergers, acquisitions and strategic alliances: Understanding the process. Basingstoke, UK: Palgrave Macmillan.

Gomes, E., Angwin, D., Peter, E., \& Mellahi, K. (2012). HRM issues and outcomes in African mergers and acquisitions: A study of the Nigerian banking sector. International Journal of Human Resource Management, 23(14), 2874-2900.

Graebner, M. E. (2004). Momentum and Serendipidity: How acquired firm leaders create value in the integration of technology firms. Strategic Management Journal, 25(8-9), 751-777.

Graebner, M. E., \& Eisenhardt, K. M. (2004). The other side of the story: Acquisition as courtship and governance as syndicate in entrepreneurial firms. Administrative Science Quarterly, 49, 366-403.

Greenwood, R., Hinings, C. R., \& Brown, J. (1994). Merging professional service firms. Organisation Science, 5(2), 239-257.

Gubbi, S. R., Aulakh, P. S., Ray, S., Sarkar, M. B., \& Chittoor, R. (2010). Do international acquisitions by emerging-economy firms create shareholder value? The case of Indian firms. Journal of International Business Studies, 41, 397-418.

Gunkel, M., Schlaegel, C., Rossteutscher, T., \& Wolff, B. (2015). The human aspect of cross-border acquisition outcomes: The role of management practices, employee emotions, and national culture. International Business Review, 24(3), 394-408.

Hajro, A. (2015). Cultural influences and the mediating role of socio-cultural integration processes on the performance of cross-border mergers and acquisitions. The International Journal of Human Resource Management, 26(2), $192-215$.

Haleblian, J., Devers, C. E., McNamara, G., Carpenter, M. A., \& Davison, R. B. (2009). Taking stock of what we know about mergers and acquisitions: A review and research agenda. Journal of Management, 35(3), 469-502.

Hitt, M., King, D., Krishnan, H., Makri, M., Schijven, M., Shimizu, K., et al. (2012). Creating value through mergers and acquisitions: Challenges and opportunities. In D. Faulkner, S. Teerikangas, \& R. Joseph (Eds.), Handbook of mergers $\mathcal{E}$ acquisitions (pp. 71-113). Oxford: Oxford University Press.

Ivancevich, J. M., Schweiger, D. M., \& Power, F. R. (1987). Strategies for managing human resources during mergers and acquisitions. Human Resource Planning, 10(1), 19-35.

Kale, P., \& Singh, H. (2012). Characteristics of emerging market mergers and acquisitions. In D. Faulkner, S. Teerikangas, \& R. Joseph (Eds.), Handbook of mergers \& acquisitions. Oxford: Oxford University Press.

Kang, J. (1993). The international market for corporate control. Journal of Financial Economics, 34, 345-371.

Kiefer, T. (2002). Understanding the emotional experience of organizational change: Evidence from a merger. Advances in Developing Human Resources, 4(1), 39-61.

Kling, G., Ghobadian, A., Hitt, M. A., Weitzel, U., \& O'Regan, N. (2014). The effects of cross-border and cross-industry mergers and acquisitions on home-region and global multinational enterprises. British Journal of Management, 25, S116-S132.

Kogut, B., \& Singh, H. (1988). The effect of culture on the choice of entry mode. Journal of International Business Studies, 19(3), 411-432.

Kolev, K., Haleblian, J., \& McNamara, G. (2012). A review of the merger and acquisition wave literature: History, antecedents, consequences and future directions. In D. Faulkner, S. Teerikangas, \& R. Joseph (Eds.), Handbook of mergers \& acquisitions (pp. 19-39). Oxford: Oxford University Press.

Lakshman, C. (2011). Post-acquisition cultural integration in mergers and acquisitions: A knowledge-based approach. Human Resource Management, 50(5), 605-623.

Larsson, R., \& Lubatkin, M. (2001). Achieving acculturation in mergers and acquisitions: An international case study. Human Relations, 54(12), 1573-1607.

Larsson, R., \& Risberg, A. (1998). Cultural awareness and national versus corporate barriers to acculturation. In M. Gertsen, A.-M. Söderberg, \& J. E. Torp (Eds.), Cultural dimensions of international mergers and acquisitions (pp. 39-56). Berlin: De Gruyter.

Malhotra, S., \& Gaur, A. S. (2014). Spatial geography and control in foreign acquisitions. Journal of International Business Studies, 45, 191-210.

Markides, C. C., \& Ittner, C. D. (1994). Shareholder benefits from corporate international diversification: Evidence from US international acquisitions. Journal of International Business Studies, 25, 343-367.

Marks, M. L., \& Mirvis, P. H. (2001). Making mergers and acquisitions work: Strategic and psychological preparation. Academy of Management Executive, 15, 80-92.

Marks, M. L., \& Mirvis, P. H. (2011). A framework for the human resources role in managing culture in mergers and acquisitions. Human Resource Management, 50(6), 859-877.

Meglio, O., \& Risberg, A. (2010). Mergers and acquisitions-time for a methodological rejuvenation of the field? Scandinavian Journal of Management, 26(1), 87-95.
Meglio, O., \& Risberg, A. (2011). The (mis)measurement of M\&A performance-A systematic narrative literature review. Scandinavian Journal of Management 27(4), 418-433.

Melkonian, T., Monin, P., \& Noorderhaven, N. G. (2011). Distributive justice, procedural justice, exemplarity, and employees' willingness to cooperate in M\&A integration processes: An analysis of the Air France-KLM merger. Human Resource Management, 50(6), 809-837.

Morosini, P., \& Singh, H. (1994). Post-cross-border acquisitions: Implementing national culture-compatible strategies to improve performance. European Management Journal, 12(4), 390-400.

Morosini, P. (1998). Managing cultural differences. Oxford: Pergamon.

Napier, N. K. (1989). Mergers and acquisitions, human resource issues and outcomes: A review and suggested typology. Journal of Management Studies, 26(3), 271-289

Olie, R. (1994). Shades of culture and institutions in international mergers. Organisation Studies, 15(3), 381-405.

Papadakis, V. M., \& Thanos, I. C. (2010). Measuring the performance of acquisitions: An empirical investigation using multiple criteria. British Journal of Management, 21(4), 859-873.

Piaskowska, D., \& Trojanowski, G. (2014). Twice as smart? The importance of managers' formative-years' international experience for their international orientation and foreign acquisition decisions. British Journal of Management, 25, 40-57.

Piekkari, R., Vaara, E., Tienari, J., \& Säntti, R. (2005). Integration or disintegration? Human resource implications of a common corporate language decision in a cross-border merger. International Journal of Human Resource Management $16(3), 330-344$

Pioch, E. (2007). 'Business as usual?' Retail employee perceptions of organizational life following cross-border acquisition. International Journal of Human Resource Management, 18/2, 209-231.

Quah, P., \& Young, S. (2005). Post-acquisition management: A phases approach for cross-border M\&A. European Management Journal, 23(1), 65-75.

Reus, T. H. (2012). Culture's consequences for emotional attending during cross-border acquisition implementation. Journal of World Business, 47, 342-351.

Sales, A., \& Mirvis, P. (1984). When cultures collide: Issues of acquisitions. In J. Kimberly \& R. Quinn (Eds.), Managing organizational transition (pp. 107-133). Homewood, IL: Irwin.

Sarala, R. M., Cooper, C., Junni, P., \& Tarba, S. (2014). A socio-cultural perspective on knowledge transfer in mergers and acquisitions. Journal of Management. http:// dx.doi.org/10.1177/0149206314530167 Advance online publication April 16, 2014.

Scheck, C. L., \& Kinicki, A. J. (2001). Identifying antecedents of coping with an organizational acquisition: A structural assessment. Journal of Organizational Behavior, 21, 627-648.

Schwartz-Shea, P., \& Yanow, D. (Eds.). (2012). Interpretive research design: Concepts and process. New York: Routledge.

Schweiger, D. M., \& Denisi, A. S. (1991). Communication with employees following a merger: A longitudinal field experiment. Academy of Management Journal, $34(1), 110-135$

Schweiger, D. M., \& Goulet, P. K. (2000). Integrating mergers and acquisitions: An international research review. In C. Cooper, \& A. Gregory (Eds.), Advances in mergers and acquisitions (Vol. 1, pp. 61-91). Amsterdam: JAI Press.

Schweizer, L. (2005). Organizational integration of acquired biotech companies into pharmaceutical companies: The need for a hybrid approach. Academy of Management Journal, 48(6), 1051-1074.

Shimizu, K., Hitt, M., Vaidyanath, D., \& Pisano, V. (2004). Theoretical foundations of cross-border mergers and acquisitions: A review of current research and recommendations for the future. Journal of International Management, 10, 307353.

Sinkovics, R. R., Zagelmeyer, S., \& Kusstatscher, V. (2011). Between merger and syndrome: The intermediary role of emotions in four cross-border M\&As. International Business Review, 21(1), 27-47

Stahl, G. K., \& Voigt, A. (2008). Do cultural differences matter in mergers and acquisitions? A tentative model and examination. Organization Science, 19(1), $160-176$.

Styhre, A., Börjesson, S., \& Wickenberg, J. (2006). Managed by the other: Cultural anxieties in two Anglo-Americanized Swedish firms. International Journal of Human Resource Management, 17(7), 1293-1306.

Teerikangas, S., \& Very, P. (2006). The culture-performance relationship in M\&A: From Yes/No to How. British Journal of Management, 17, S31-S48.

Teerikangas, S., Very, P., \& Pisano, V. (2011). Integration managers' value capturing role and acquisition performance. Human Resource Management, 50(5), 651683.

Teerikangas, S. (2012). Dynamics of acquired firms' pre-acquisition employee reactions. Journal of Management, 38(2), 599-639.

Teerikangas, S., \& Véry, P. (2012). Culture in mergers and acquisitions: A critical synthesis and steps forward. In D. Faulkner, S. Teerikangas, \& R. Joseph (Eds.) Handbook of mergers \& acquisitions (pp. 392-430). Oxford: Oxford University Press.

Thanos, I. C., \& Papadakis, V. M. (2012). Unbundling acquisition performance: How do they perform and how can this be measured? In D. Faulkner, S. Teerikangas, \& R. Joseph (Eds.), Handbook of mergers E acquisitions (pp. 114-147). Oxford: Oxford University Press. 
Vaara, E., Tienari, J., Piekkari, R., \& Säntti, R. (2005). Language and the circuits of power in a merging multinational corporation. Journal of Management Studies, 42(3), 595-623.

Vaara, E., Sarala, R. M., Stahl, G., \& Bjorkman, I. (2012). The impact of organizational and national cultural differences on social conflict and knowledge transfer in international acquisitions. Journal of Management Studies, 49(1).

Vaara, E., Junni, P., Sarala, R. M., Ehrnrooth, M., \& Koveshnikov, A. (2014). Attributional tendencies in cultural explanations of M\&A performance. Strategic Management Journal, 35, 1302-1317.

Van Dick, R., Wagner, U., \& Lemmer, G. (2004). Research note: The winds of change-Multiple identifications in the case of organizational mergers. European Journal of Work and Organizational Psychology, 13(2), 121-138.

Van Maanen, J. (1988). Tales of the field: On writing ethnography. Chicago: University of Chicago Press.

Véry, P., Lubatkin, M., \& Calori, R. (1996). A cross-national assessment of acculturative stress in recent European mergers. International Studies of Management and Organisation, 26, 59-86.

Watson, T. (2012). Making organisational ethnography. Journal of Organizational Ethnography, 1(1), 15-22.

Weber, Y., Shenkar, O., \& Raveh, A. (1996). National and corporate cultural fit in mergers/acquisitions: An exploratory study. Management Science, 42, 12151227.
Weber, Y., \& Fried, Y. (2011a). The role of HR practices in managing culture clash during the post-merger integration process. Human Resource Management, 50(5), 565-570.

Weber, Y., \& Fried, Y. (2011b). The dynamic of employees' reactions during post-merger integration process. Human Resource Management, 50(6), 777 781.

Weber, Y., \& Tarba, S. Y. (2011). Exploring integration approach in related mergers International Journal of Organizational Analysis, 19(3), 202-221.

Weber, Y., Tarba, S. Y., \& Reichel, A. (2009). International mergers and acquisitions performance revisited - The role of cultural distance and post-acquisition integration approach implementation. Advances in Mergers and Acquisitions, 8, $1-18$.

Weber, Y., Tarba, S. Y., \& Reichel, A. (2011). A model of the influence of culture on integration approaches and international mergers and acquisitions performance. International Studies of Management and Organization, 41(3), 9-24

Weber, Y., Rachman-Moore, D., \& Tarba, S. Y. (2012). Human resource practices during post-merger conflict and merger performance. International Journal of Cross-Cultural Management, 12(1), 73-99.

Zeng, Y., Shenkar, O., Seung-Hyun Lee, S., \& Song, S. (2013). Cultural differences, MNE learning abilities, and the effect of experience on subsidiary mortality in a dissimilar culture: Evidence from Korean MNEs. Journal of International Business Studies, 44, 42-65. 